\title{
artículos
}

\section{Las reliquias de San Flaviano de la Catedral de Málaga. Arte, iconografía, traslación y culto}

\author{
Alberto Jesús Palomo Cruz \\ Archivo Catedral de Málaga
}

RESUMEN

Se analiza el origen y procedencia de las reliquias de San Flaviano, conservadas en la Catedral de Málaga, cuya veneración ha oscilado entre el fervor del Barroco a la respetuosa indiferencia de la actualidad.

PALABRAS CLAVE: Reliquias/ San Flaviano/ Catedral de Málaga. and cult

Saint Flaviano's relics in Cathedral of Málaga: Art, iconography, removal

ABSTRACT

Preserved in Malaga Cathedral, the relics of Saint Flaviano, have oscillated between the devotion of the Baroque and the indifference of nowadays.

KEY WORDS: Relics/ Saint Flaviano/ Cathedral of Málaga.

\section{A MODO DE INTRODUCCIÓN.}

SANCTORVM OSSA DAEMONES SISTVNT ACTOR QNT. Esta frase, tomada de uno de los sermones de San Juan Crisóstomo y contenida en el llamado Breviarium molinense., aparece inscrita en uno de los relieves que adornan la puerta de la antigua taca del tesoro de la catedral malagueña, situada en su sacristía mayor. En ella se resume la importancia que para la Iglesia ha tenido siempre y muy especialmente en siglos pasados la veneración de las reliquias, capaces de poner en fuga a los demonios y hacerlos temblar, como indica la traducción aproximada del antecedente texto latino. El clero de la catedral malagueña, como el de cualquier otra en el pasado, quiso hacerse de un buen número de ellas buscando el prestigio de la iglesia mayor a la que estaban adscritas y poder así también atender las periódicas consagraciones de nuevas aras. Con todo, pese a las desorbitadas descripciones de la mayoría de los historiadores locales que siempre se refirieron al rico tesoro que poseía el cabildo malacitano de relicarios, la realidad es que la catedral malacitana no pasó nuca de contar con un discreto número de tales, casi todos con una importancia religiosa y artística relativas, salvo algunas excepciones evidentes. Apreciación ésta que no formulamos nosotros, sino que viene constatada por un escrito capitular del siglo

* PALOMO CRUZ, Alberto Jesús: "Las reliquias de San Flaviano de la Catedral de Málaga. Arte, iconografía traslación y culto", en Boletín de Arte $n^{\circ} 32-33$, Departamento de Historia del Arte, Universidad de Málaga, 2011-2012, págs. 529-542. Fecha de recepción: Julio de 2010. 
XVIII, en el cual los canónigos agradecen cualquier donación en este sentido y más "(...) cuando es tanta la escasez de reliquias en esta iglesia, como no se ignora (...)"1.

De hecho, obviando la reliquia del Santo Lignum Crucis, que en los antiguos inventarios de sacristía especifican que provenía del trozo regalado por Carlos I a las Descalzas Reales de Madrid², el primer templo malagueño sólo pudo contar con unas cuantas reliquias insignes, entendiendo como tales la clasificación jurídica de esta denominación sólo aplicada a los cuerpos de los santos o miembros importantes de los mismos. De todas éstas, algunas, como es el caso del relicario que guarda la cabeza de una de las supuestas once mil vírgenes que acompañaron a Santa Úrsula al martirio, no dejan de ser más que dudosas, a la vista de los actuales estudios hagiográficos y la ausencia de auténtica o de cualquier documentación que avale su procedencia o validez de su culto.

De entre todas estas reliquias principales custodiadas en la catedral, destaca, por varios conceptos, el cuerpo de San Flaviano contenido en una arca de madera oscura con apliques de bronce, que también guarda una canilla y una redoma pequeña de vidrio con sangre de Santa Justina, aunque obviaremos hablar de ella en el presente trabajo para centrarnos solamente en el santo mártir en cuestión.

\section{RECEPCIÓN DE LAS RELIQUIAS.}

Que el cuerpo de San Flaviano se conserve en la catedral malagueña se debe a la munificencia del cardenal fray Pedro de Salazar, malagueño de ilustre y noble familia y que fue considerado uno de los prelados españoles más relevantes del siglo XVII y del que nos parece oportuno recordar algunos hitos de su vida. Se formó en Salamanca donde se ordenó e ingresó en la orden mercedaria en 1647. Concluidos sus estudios universitarios regresó a Andalucía donde ejerció la docencia en Jaén, en Málaga y, ya como rector de estudios y comendador de su orden, en Sevilla, hacia 1665. La fama de su oratoria hizo que fuese nombrado predicador regio de los monarcas Felipe IV y Carlos II. Llegó a ser maestro general de la religión mercedaria entre los años 1670 a 1676. Cuatro años más tarde fue nombrado obispo de Salamanca y, en 1686, trasladado a Córdoba y nombrado cardenal de la Iglesia con el título de la Santa Cruz en Jerusalén. En la antigua ciudad califal desplegó una ingente tarea apostólica, además de revelarse como un generoso mecenas que costeó, entre otras obras, el famoso hospital conocido como el del cardenal y la construcción de la capilla de Santa Teresa en la catedralmezquita, donde a la postre fue enterrado en el aparatoso mausoleo con resabios de sepulcro papal que allí todavía se puede admirar. También sufragó los órganos y

1 (A)rchivo (C)atedral de (M)álaga. Actas Capitulares (AA.CC.) 29 de mayo de 1708, fol. 288.

2 A.C.M. Leg. 838. También diversos estudiosos locales corroboran la procedencia madrileña de esta santa reliquia. Vid.: M. BOLEA SINTAS, La catedral de Málaga, Málaga 1898, p. 263. 
un riquísimo frontal de plata para el mismo templo, aunque este último no podemos disfrutarlo por haber sido rapiñado por los franceses en 1810. Queremos destacar por último que fray Pedro, por su condición cardenalicia, residió varias temporadas en Roma, donde tuvo la oportunidad de participar en los cónclaves que eligieron a los pontífices Alejandro VIII e Inocencio XII. Precisamente de una de estas estancias en la corte papal debemos encuadrar la obtención y posterior donación del relicario insigne de San Flaviano, que llegó a Málaga, acompañado del documento de certificación y entrega, el 15 de septiembre de 1697, según informó el deán, Francisco de Aranda y Guzmán, en el transcurso de un cabildo en el que se acordó escribir al prelado dándole por ello las gracias más expresivas. Igualmente se dispuso que el santo cuerpo:

"(..) se coloque por ahora en la sacristía mayor hasta que se determine en que altar se ha de colocar y en qué día se ha de rezar. Y que el dicho testimonio se inscriba en el inventario de bulas del archivo de esta santa iglesia y se ponga original en el legajo correspondiente quedando un traslado autorizado de él para ponerse dentro de la urna. Y se responda a su eminencia dándole las gracias por la remisión de dicha reliquia"3.

No obstante, un mes más tarde el secretario capitular, estrictamente escrupuloso y metódico, hizo saber a los canónigos que habiendo reconocido el escrito que había remitido el cardenal Salazar había encontrado una omisión en su contenido que había tenido que subsanar:

“(...) confirmó que se había recibido la urna con el cuerpo de San Flaviano (...) que traía una canilla grande de Santa Justina y una redomita depósito de sangre, lo que no venía expreso en el testimonio del señor cardenal. Que le había escrito a su secretario dándole a entender, por si había sido olvido, lo expresase y le pidió dicho testimonio y ha remitido otro en que se contienen ambas reliquias (...)"4.

El documento en cuestión, que es el que se conserva en el archivo catedralicio, quedó corregido con la mención de las reliquias de la referida mártir, aunque no se cambió la fecha de expedición del escrito que le antecedió y que se juzgó incompleto. El texto definitivo dice así:

"Pedro, porla Divina Misericordia de la Santa Iglesia de Roma, presbitero cardenal Salazar del título de la Santa Cruz de Jerusalén, obispo de Córdoba, del consejo de S. M: Por cuanto entre diferentes reliquias que trajimos a España de las que nos dieron en la santa ciudad de Roma al tiempo de nuestra residencia en aquella corte, fue una de las más principales el cuerpo de San Flaviano mártir colocado en una urna negra con guarniciones y remates dorados, dentro de la cual está una canilla de Santa Justina mártir y una vasija pequeña en forma de redomita con su cuello, dado un barniz o baño

3 A.C.M. AA.CC. 15 de septiembre de 1697, fol. 219 v.

4 A.C.M. AA.CC.16 de octubre de 1697, fol. 226 v. 
como azul; la cual fue un depósito de la sangre de la misma santa mártir Justina que se halló con su cuerpo; y la dicha urna está dispuesta con vidrieras cristalinas, por donde se pueda cómodamente gozar y adorar dichas santas reliquias. Por tanto, deseando manifestar en algún modo nuestro cordial amor y veneración a la santa iglesia catedral de la ciudad de Málaga, nuestra patria, remitimos y donamos la dicha urna, en que está el dicho cuerpo de San Flaviano mártir y las reliquias referidas de Santa Justina, al M.I.S. deán y cabildo de dicha santa iglesia de Málaga, por medio del señor don Martín Rico de Córdoba maestrescuela, dignidad y canónigo de dicha ciudad, para que en nuestro nombre la presente a dichos señores y se sirvan de colocarla en la parte que más decente y conveniente juzgaren. Y porque en todo tiempo conste así de la autoridad de dicha reliquia y santo cuerpo, como de nuestra libre donación; mandamos dar el presente instrumento firmado de nuestra mano, sellado con el sello de nuestras armas y refrendado de nuestro secretario de cámara en Córdoba, en nuestro palacio episcopal a 9 días del mes de septiembre de 1697 años"5.

En la misma sesión capitular en la que se había tratado de las enmiendas a este certificado, se trató también, previo aviso al obispo Bartolomé Espejo y Cisneros, sobre el rezo y festividades de estos dos mártires, disponiéndose al respecto que:

“(...) el día de San Flaviano que es a 22 de diciembre, se saque la dicha urna de la sacristía y se lleve en procesión por la iglesia cantando villancicos y se coloque en el altar mayor y se digan las misas con toda solemnidad, y si pareciere a su ilustrísima que haya sermón, se sirva de encomendarlo. Y después se guarde en la sacristía con toda decencia en el ínterin que se procura adornar una capilla donde colocar la urna para la adoración pública y consuelo del pueblo".

\section{Vida de San Flaviano.}

En la documentación existente sobre la donación de esta reliquia insigne no se hace mención alguna sobre esta cuestión, ni siquiera alusión específica alguna a los hechos y méritos de San Flaviano. Sin embargo, la fecha fijada para celebrar su festividad por el cabildo, y que además aparece inscrita en un tarjetón de bronce que figura en la arqueta relicario nos remite a uno de los mártires romanos de este nombre que vivió en el siglo IV ${ }^{7}$, padre a su vez de las bienaventuradas Bibiana y Demetria

5 A.C.M. Leg. 35, pza. 74. No era esta la primera vez que un hijo de Málaga con un alto rango eclesiástico favoreciera a la catedral con donaciones semejantes. Ya en junio de 1555 por mano del arcediano Francisco de Torres, el cabildo recibió la entrega de reliquias de la categoría de los santos Pedro, Pablo, Andrés, Bartolomé, Mateo, Lucas, Marcos, Juan, Sebastián, Esteban, Jerónimo, Buenaventura, Cosme, Damián, Nicolás, Catalina, Inés, Águeda... entre otras muchas. DÍAZ ESCOVAR, N.: Efemérides malagueñas, Málaga s. d. Cf.: A.C.M. Leg. 159 , pza. 2, f. 416 v. $n^{\circ} .54$.

6 A.C.M. AA.CC. 16 de octubre de 1697, fol. 226 v.

7 Hay varios santos de este nombre, que además coinciden en algunos otros aspectos con el que nos interesa, por lo que es mayor la confusión. Así ocurre con un San Flaviano, que también llegó a ser prefecto de la ciudad eterna, y murió allí mártir durante la persecución de Diocleciano, celebrándose su fiesta el 28 de enero. 
y esposo que fue de Santa Dafrosia, según recoge la noticia contenida en la Passio S. Bibianae, que de paso aporta unos datos muy precisos sobre nuestro santo y que iremos desarrollando más adelante ${ }^{8}$. Los diversos santorales no aportan dato alguno sobre su infancia o juventud, limitándose a recoger que provenía de una familia antigua e ilustre de la ciudad imperial que había abrazado la fe de Cristo. Llegó a ser prefecto de Roma, magistratura que no le impidió, según registran diversos hagiógrafos, entregarse a una vida marcada por la piedad y la caridad. Por desgracia, cuando accedió al poder Flavio Julio Constancio, hijo de Constantino, las cosas se complicaron para Flaviano que no se avino a seguir las doctrinas arrianas con las cuales simpatizaba el nuevo emperador, instigado principalmente por su esposa Eusebia. Como prefecto de la urbe, nuestro personaje era demasiado ilustre, además de destacado atanasiano, para no verse inmiscuido en las severas represalias religiosas que se siguieron, hacia el año 350. Fue privado de su empleo, alejado de la corte imperial y obligado a arrastrar una existencia modesta. Con todo, lo peor le acontecería cuando en 361, muerto Constancio, el helenista Flavio Claudio Juliano, al que los historiadores cristianos bautizarían como Juliano el Apóstata, que había sido creado césar el año 355, quedó como único dueño del imperio. Su gobierno estuvo caracterizado por su propósito de restablecer el culto olímpico y, pese a que en líneas generales no se mostró cruel con los cristianos, suprimió todos los privilegios de la, por entonces, joven Iglesia, vetando a sus miembros para el desempeño de la enseñanza o los cargos públicos. Precisamente, el autor de una famosa biografía novelada de este emperador pone precisamente en los labios imperiales el siguiente comentario:

"Difícilmente podía esperarse que un gobernador que simpatizase con los galileos pusiese en vigor mis edictos (...) algunos senadores me censuraron en los debates ¿por qué, si yo era tolerante con todas las religiones, perseguía a los funcionarios galileos? (...) pero, ¿Cómo puede ser gobernador un galileo cuando el Nazareno le ha ordenado expresamente no tomar la vida de nadie, como puede verse en ese libro que, según se dice es de Mateo (...) y otra vez en la obra del escritor Juan? Siempre uso sus propias armas para luchar contra ellos. Ellos usan las nuestras para atacarnos".

Al amparo de esta corriente crítica para la cristiandad y ventajosa para la gentilidad, muchos burócratas estatales se extralimitaron en su celo por complacer los deseos de Juliano. Uno de ellos fue el sucesor de Flaviano en la magistratura de Roma, un tal Apronio, que irritado contra éste por su gran actividad proselitista, lo hizo prender

Vid: AA.VV.: La leyenda de oro para cada día del año, Barcelona 1865, pág. 244.

8 (...) huius ergo temporibus erat quidam vir illustris prefectus urbis nomine Flavianus cum uxori nomine Dafrosa et duabus filiabas quórum una Dimitria alia Viviana vocabatur que nutrite fuerant sub ovni castitate et fide (...) tunc lulianus imperator in scriptione Flavianum damnari precepit, et omnes facultates eius fisco sociari. Ipsum quoque ad Aquas Taurinas sexagesimo miliario ab urbe Roma, via Claudia in exilium deportari precepit, qui triduo postquam decessus in exiluim in oratione permanens, ieiunians dormitionem accepit in Domino die undecima calendarium januarium (...)". Vid.: PACETTI, La basilica di S. Flaviano a Montefiascone, Roma 1992 Otro autor que trata sobre esta santa parentela es N. SCHLEINIGER.: La acción civilizadora de la Iglesia, Buenos Aires 1945, pág. 27.

9 VIDAL, G.: Juliano el Apóstata, Barcelona, 1988, pág. 344. 
con la intención de convencerle a renegar de la fe. Todos sus intentos fueron vanos, porque el santo se mantuvo firme y constante, de tal modo que el prefecto acabó por arrebatarle los pocos bienes que le quedaban y le hizo marcar en la frente con un hierro, como se solía practicar con los esclavos o los más infames criminales. Finalmente, lo condenó al destierro de por vida, confinándolo en un lugar denominado Acquæ Taurinæ, donde poco después, un 22 de diciembre, su dies natalis, falleció santamente ${ }^{10}$.

\section{Condición de mártir de San Flaviano.}

Como hemos podido comprobar San Flaviano no llegó a sufrir la pena de muerte por su condición de cristiano, por lo que en algunos santorales figura explícitamente con el título de confesor ${ }^{11}$. Pero en la mayoría de los textos prevalece el término de mártir equiparando su culto al de ellos como se explica en una de las narraciones de su vida:

"Como murió de las miserias que padeció en su destierro, ha sido mirado en la Iglesia como un gloriosos mártir de Jesucristo; así como otros muchos que no perdieron la vida con el hierro ni con el fuego, los cuales no dejan por eso de ser honrados como mártires por la Iglesia"12.

Aunque es cierto que los escritores eclesiásticos desde muy antiguo establecieron diferencias entre los mártires y los confesores, cabe recordar como en una primera época el nombre de confesor fue usado por los santos padres como sinónimo para los mártires, como se puede comprobar leyendo a autores como San Ambrosio o San Paulino de Nola. También de los escritos de Tertuliano se puede colegir que para él confesores et martyres no eran dos categorías de personas sino una sola, pese a que cabe la sospecha de que cuando usa de este primer término “(...) quiera poner el énfasis en la confesión de la fe ante un magistrado pagano y sólo secundariamente se refiera a la muerte del mártir, con que aquella confesión queda confirmada, en martyr, en cambio, el acento recae sobre los tormentos y muerte que el cristiano sufre por la confesión de la fe... ${ }^{13}$.

Después de todo consideremos como hasta el edicto de Constantino la pública protestación de la fe cristiana, en según qué periodos, era considerada por las autoridades como un delito suficiente para que quien la pronunciase pudiese ser enjuiciado, torturado o ejecutado.

10 Las distintas fuentes hagiográficas discrepan en cuanto al año de su óbito, las más la sitúan en 361, sospechosamente el mismo año en que accedió al poder imperial Juliano el Apóstata, lo que significaría que el proceso, destierro y muerte del santo acaeció en un corto espacio de tiempo.

11 AA.VV.: La leyenda de oro para cada día del año, Barcelona 1866, tomo III, pág. 624.

12 AA.VV.: Año cristiano o ejercicios devotos para todos los días del año, Madrid 1818, pág. 351.

13 RUIZ BUENO, D.: Actas de los mártires, Madrid 1962, pág. 16. 
Procedencia de las reliquias de San Flaviano.

Todo parece indicar que el santo que historiamos fue sepultado en el lugar donde estuvo confinado, Acquæ Taurinæ, voz genérica de muchos enclaves del mundo clásico que nos remite a los baños o manantiales que debían de existir en su proximidad. En este sitio cerca del lago Bolsena, hoy distrito de Viterbo, se estableció una pequeña población, cuyo nombre trasmutado y en relación con San Flaviano,. ya aparece reflejada en un privilegio del papa León IV redactado entre los años 847 y 853 :

"Certissime igitur corroboramos et modis ómnibus confirmamos tibi (...) ecclesiam Sanctae Marie ubi corpus beati Flaviani martiris requiescit, cum casale et burgo suo in circuito et giro ejes (...) vallen episcopii, montem Fiasconis inde (...) ${ }^{14 "}$.

Tuvieron que pasar, aproximadamente cinco siglos, para que en 1369 la diócesis de Montefiascone fuese creada, siendo su primer prelado el agustino francés Pedro D'Anquiscen. Para entonces ya era antigua la basílica martirial allí erigida y dedicada en honor de San Flaviano y que presumía de albergar la tumba del mismo. Sin embargo, según colegimos de los testimonios conservados, con el paso del tiempo, las vicisitudes históricas y las sucesivas reedificaciones y modificaciones del mencionado edificio el lugar donde reposaban las reliquias no estaba del todo definido ${ }^{15}$. Tanto es así, que en el acta que registró la visita pastoral del obispo Gaspare Cecchinelli, en diciembre de 1630 , se expresa vagamente que en la zona del altar mayor es donde “(..) si credeva che fossero conservate le reliquie di San Flaviano"16.

Esta evidente nebulosa ha llegado hasta nuestros días de tal modo que en la actualidad el único testigo de la permanencia de la osamenta del mártir en la iglesia de Montefiascone está constituida por un fragmento marmóreo con la inscripción CORPUS S FLAVIANI, recientemente fijada en el presbiterio y que se supone formaba parte de una ventanilla cuya obertura posibilitaba a los fieles el poder tocar las sacras reliquias ${ }^{17}$.

No hay ningún indicio documental directo del que sepamos que nos haga sospechar que, en algún momento indeterminado y por causas no especificadas, estas reliquias fueran trasladadas desde su secular lugar de veneración hasta Roma, donde finalmente llegarían al poder del obispo Pedro de Salazar. Sin embargo, esto nos da pie a recoger la noticia de que al menos en dos ocasiones singulares, como en el siglo $\mathrm{V}$ con motivo de las invasiones llevadas a cabo por Alarico y posteriormente en el transcurso

14 De hecho, el burgo que fue creciendo en torno a la iglesia que albergaba sus reliquias se denominó originaria e indistintamente como Montefiascone o con el nombre del referido santo mártir. BRECCOLA, V.G.: Basilica di San Flaviano, Viterbo 1996, pág. 5.

15 El ejemplo más cercano a esta insólita ignorancia del lugar donde se encontraba las reliquias de San Flaviano, la encontramos en el dilatado espacio en que anduvieron perdidas, nada menos, que las del apóstol Santiago en Compostela.

16 L.C.

17 O. c., p. 25. 
del siglo IX, numerosas reliquias de mártires fueron trasladadas desde sus enclaves de veneración en las cercanías de Roma para ser depositadas en la basílica vaticana con el fin de evitar su destrucción, como ocurrió en el caso de San Sebastián ${ }^{18}$. Por consiguiente, se podría suponer razonablemente que las del prefecto Flaviano se llevasen del mismo modo hasta la Urbe para resguardarlas y allí se quedasen hasta que el cardenal Salazar se interesó por ellas. Mientras en la pequeña ciudad de Montefiascone sólo quedaría el recuerdo de la sepultura del santo y unos pocos testimonios arqueológicos relacionados con ella. Incógnitas que quedan sin desvelar, a la espera de que los estudiosos de estos temas, principalmente italianos, arrojen alguna luz al respecto. Sin lugar a dudas el nexo más incontestable que relaciona estas reliquias con las existentes en Málaga es la fecha que, tanto en la urna que las contiene como en el acuerdo capitular que tomaron los canónigos malagueños, coincide con la establecida por la Iglesia para celebrar la festividad de San Flaviano. Por supuesto, cabe la posibilidad de que los restos en disputa provengan de algunos de los cementerios romanos que a raíz del redescubrimiento en 1578 de las catacumbas reavivaron el fervor contrarreformista por las reliquias ${ }^{19}$.

Ciertamente, en la misma catedral malacitana se veneraron los cuerpos de los bienaventurados Félix y Dianesa, de los que sabemos con certidumbre que fueron extraídos del camposanto de San Saturnino de Roma en 1736 y que, por el mero hecho de haber estado sepultados allí, se les consideró santos, como fue la práctica universal que se seguía por aquellas fechas ${ }^{20}$. Pero pese a todo, no es razonable pensar que el simple descubrimiento en alguna catacumba de un difunto denominado Flaviano, fuese suficiente argumento para identificarlo con el que llegó a ser prefecto de la ciudad y víctima de las represalias de los emperadores Constancio y Juliano. Después de todo, Montefiascone está lo suficientemente cerca de la Ciudad Eterna, de hecho pertenece a la diócesis romana, como para que los encargados eclesiásticos de la distribución de reliquias ignorasen la tradición que situaba el enterramiento del santo en el área aproximada al sitio donde soportó su destierro.

\section{El culto a San Flaviano en la catedral malacitana.}

Desconocemos si los enigmas que rodean a las reliquias que venimos tratando afectaron al valor devocional y al culto que recibieron por parte de los capitulares, porque es evidente que progresivamente el fervor hacia ellas dirigido fue decreciendo.

18 FERNÁNDEZ CATÓN, J.Ma .: "El culto de las reliquias: Crítica hagiográfica, fuentes e historia", en Memoria Ecclesiae XXV, Oviedo 2004, págs. 65 y 66.

19 El hecho de que el cuerpo de San Flaviano esté acompañado por las reliquias de Santa Justina, especialmente con la botellita que contiene su sangre, así como restos menores provenientes de diversos santos, parecen indicar la posibilidad de que provengan de alguna catacumba. Si es así, al coincidir los restos que llegaron a Málaga con el nombre del que fue prefecto de Roma, quedó asimilado a él, compartiendo su misma festividad, aunque se tratase evidentemente de dos personajes diferentes.

20 El primero de los cuerpos desapareció en las rapiñas de la guerra civil, el de Santa Dianesa sí se conserva, aunque por las mismas fechas fue despojada de la rica urna que lo contenía. Sus auténticas se conservan en A.C.M. Leg. 35, pza. 77. 
De los obsequios que se le tributaron en las fechas cercanas a su recepción y que, recordemos, incluía procesión claustral y villancicos, se pasó en la segunda mitad del siglo XVIII a observar un discreto protocolo. Por ese tiempo el arca de las reliquias, era trasladada hasta el altar mayor en la tarde del día 21 de diciembre, período de adviento, encendiéndoseles sólo "(...) dos luces desde las primeras vísperas, hasta después de maitines (...) pero no hay procesión ni adoración"21. Todavía en la epactas diocesanas de la centuria siguiente recogían lacónicamente la mención de la festividad:

"December. 22 Fer. 4 In Cath. S. Flavian. M. dp. Rub (Reliq. Insign II. 1 n. Scr. In $2^{\circ}$ oct. Triumphalis: in $3^{\circ}$. Homil. In Ev. Nolite arbitrari: com. Fer. In laud et Miss. In virtute: Cr. In Cath. Tant. In Vp. Á cap. Sq. Mer. Supr. Aña. O Doctor: com. Ant. Et fer. Aña. O Rex. alb"22.

Sin embargo, a partir ya del pontificado del beato Marcelo Spínola y Maestre, que tomó posesión de la silla episcopal el 8 de septiembre de 1886, los directorios litúrgicos omiten toda mención a la festividad de San Flaviano, sustituido por el de la virgen y mártir Eulalia, sin vinculación alguna con esta iglesia local ${ }^{23}$. Desde entonces, tanto la memoria del santo como la arqueta que contiene sus restos no pasan de ser una anécdota ocasional para quienes tienen la ocasión de admirar la taca de la sacristía que atesora en la actualidad la mayor parte de las reliquias que custodia la catedral.

No debemos omitir que la veneración que otrora recibió este santo en Málaga no llegó a producir, que sepamos, ninguna representación iconográfica del mismo, siquiera fuera en humilde estampa. En Montefiascone, en la iglesia a él dedicada, sí existen varios frescos góticos que lo representan anacrónicamente con atuendo de cortesano medieval e, incluso, a caballo con un grafismo parecido al de San Jorge de Capadocia, lo que cabe interpretar con la pretensión del artista de representarlo como un destacado caballero por la causa de Cristo. Curiosamente en nuestros días al doctor por la Universidad malacitana, Juan Antonio Sánchez López se le debe la única imagen que de San Flaviano podemos contemplar en la ciudad de Málaga. Este reconocido profesor en Historia del Arte, destacado dibujante y diseñador, recibió el encargo por parte de la hermandad penitencial del Sagrado Descendimiento de realizar el proyecto del nuevo trono procesional de su titular María Santísima de las Angustias. En el elaborado programa iconográfico ideado por él, elaboró una galería de santos en relación con la diócesis, incluyendo entre ellos a este mártir. La pieza en cuestión es un hermoso esmalte elaborado en los talleres de Granda de Madrid, que según las indicaciones recibidas reproduce uno de los personajes del celebrado cuadro Abrahán y los tres ángeles, obra de Murillo, adaptándose en este caso la inscripción: SAN FLAVIANO MÁRTIR.

21 A.C.M. Leg. 883, pza. 1, Prontuario ceremonial para el uso de la sacristía mayor, fols. 47 v. y 48 v, año 1778.

22 Kalendarium S. Ecc. Et Diócesis Malacitanae, Málaga 1852, pág. 74.

23 Kalendarium perpetuum pro Ecclesia et Diocesi Malacitanae, Málaga 1890, pág. 23. 


\begin{tabular}{|c|c|}
\hline 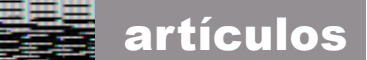 & Alberto Jesús Palomo Cruz \\
\hline
\end{tabular}

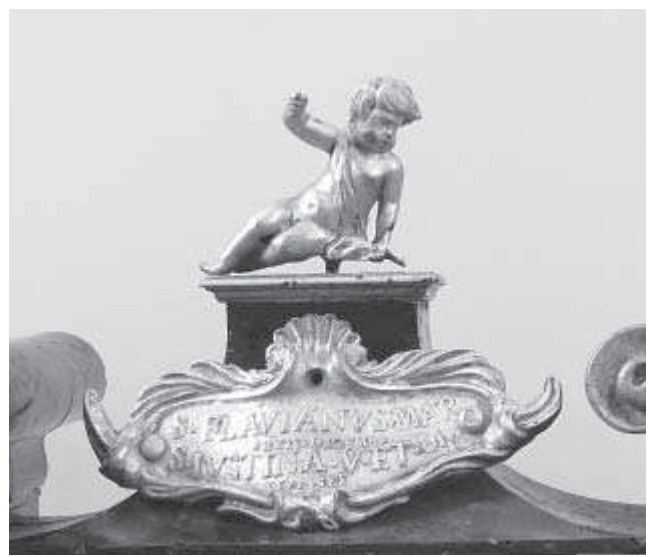

1. Angelito y cartela.
También hace pocos años estuvoapunto deserrepresentado, junto a otros santos de la tierra, en el respiradero de plata que comenzó a labrarse por la escuela taller "Molina Lario", propia de la catedral de Málaga, con destino a la custodia procesional del Corpus Christi. Finalmente el proyecto fue desechado, aprobándose en cambio un programa iconográfico de lo más anodino.

\section{LA ARQUETA RELICARIO.}

En los antiguos inventarios de la sacristía mayor al tratar de esta pieza, especifican todos que la misma es de madera de peral ${ }^{24}$. En muy buen estado de conservación, sin ataque aparente de xilófagos, el arca del cuerpo de San Flaviano es una caja rectangular de dos cuerpos, que presenta en el superior un remate en forma de pirámide truncada con cristales que permiten observar un hueso que pertenece a Santa Justina. Igualmente en los laterales exteriores de la urna existen sendas vitrinas con un fondo forrado o pintado en color rojo que muestra una serie de reliquias menores, que más a delante detallaremos. El conjunto confeccionado en madera lacada en negro, presenta unos meritorios relieves en bronce dorado entre los que destacan dos figuras atlantes flanqueando la portezuela y las siluetas de dos angelitos que blanden una guirnalda de flores y una palma, alusivas al carácter de los santos cuyas reliquias allí están depositadas. La arqueta aparece sustentada por dos simples pomos de madera en su parte posterior, que en la delantera se convierten en dos garras leoninas también fundidas en el mencionado metal, en medio de las cuales aparece la escultura de un pequeño felino broncíneo cuya postura hace ademán de sustentar el peso del relicario, que aproximadamente mide en su parte frontal 54 de ancho, por 72 de alto y de fondo 31 centímetros. Como remate de todo el conjunto, sobre el frontón partido de la parte superior, se nos muestra la estatuilla en bronce de un angelito recostado cuya mano derecha se encuentra alzada y con indicios de habar portado en origen algún adorno o atributo que no ha llegado hasta nosotros. Colocada bajo él figura una cartela orlada con palmas y una venera con una inscripción que expresa: S.FLAVIANVS. MAR. XXII. DECEMB. S. IVSTINA. V. ET. M. XXVI. SEPT. Esta pieza también está fundida en bronce, así como las molduras y cantoneras de la portezuela que presenta la correspondiente cerradura. Una vez abierta la urna, se nos revelan los restos del santo, destacando su calavera coronada con una fimbria de

24 A.C.M. Leg. 231, pza. 6, Inventario de la sacristía mayor, 1785. 


\begin{tabular}{|c|c|c|}
\hline 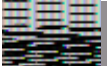 & artículos & Las reliquias de San Flaviano de la Catedral de Málaga... \\
\hline
\end{tabular}
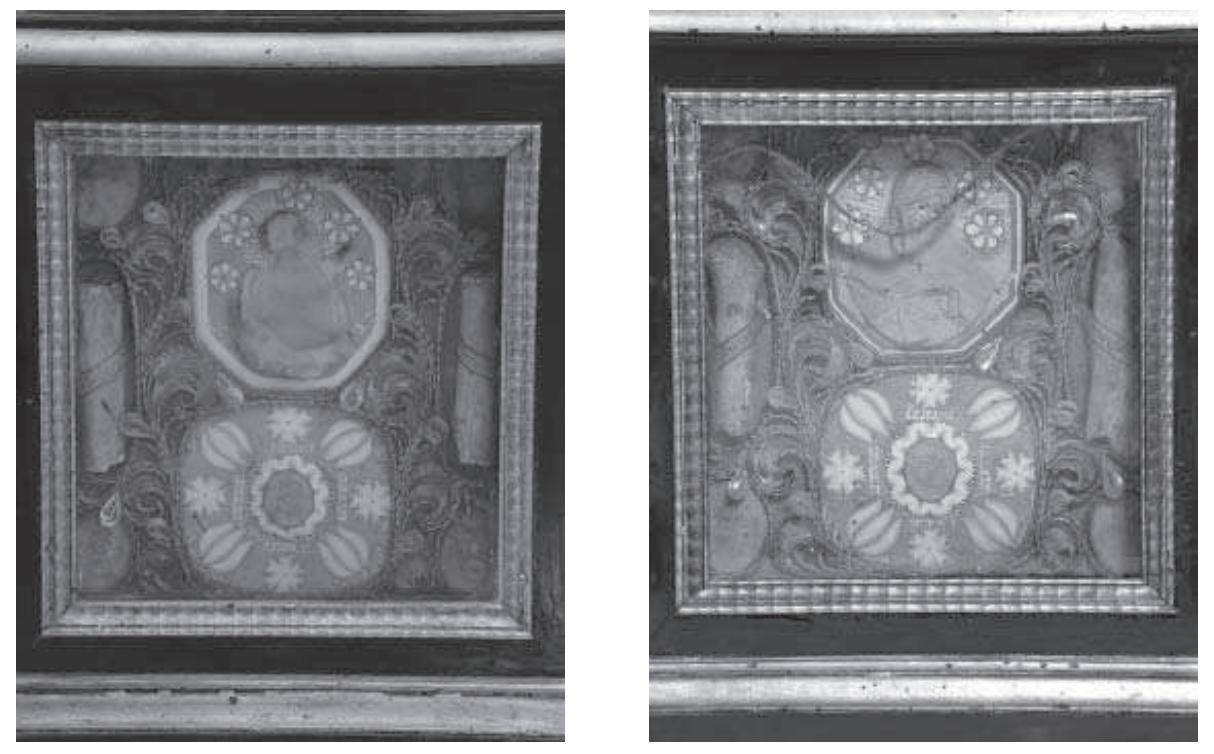

2. Lateral derecho.

3. Lateral izquierdo.

flores de seda y una cinta de tela en su frente que repite su nombre y condición de mártir. El resto del material óseo se encuentra muy fragmentado, conformando los elementos mayores unos adornos en formas de aspas y estando los restantes colocados siguiendo cierta estética. El tapizado en papel o tafetán rojo y la inclusión de flores realizadas en agremanes y otros abalorios completan la presentación de las reliquias, todas convenientemente fijadas y adheridas. A falta de un estudio antropológico de algún especialista forense, se puede descubrir básicamente que se trata de un individuo adulto ya que en la dentadura, sorprendentemente completa y sin signos aparentes de deterioros o lesiones dentarias, se observan los premolares y molares desarrollados.

En los documentos del archivo capitular hemos podido descubrir que en ocasiones se han extraído de la arqueta, oficial u oficiosamente, algunas partes de las reliquias. Ya al año siguiente de la llegada de estos restos sacros a la catedral los canónigos se vieron en la obligación de acordar que: "(...)las reliquias del cuerpo entero de San Flaviano mártir y Santa Justina que envió el cardenal Salazar, y la reliquia de San Lorenzo y la de San Mauricio y otras que hay en la sacristía mayor de esta santa iglesia se pongan en custodia y se guarden con su llave, porque se van disminuyendo, de lo que el deán se encargará de ello(... $)^{25 "}$.

25 A.C.M. AA.CC. 26 de agosto de 1688, fol. 274. 


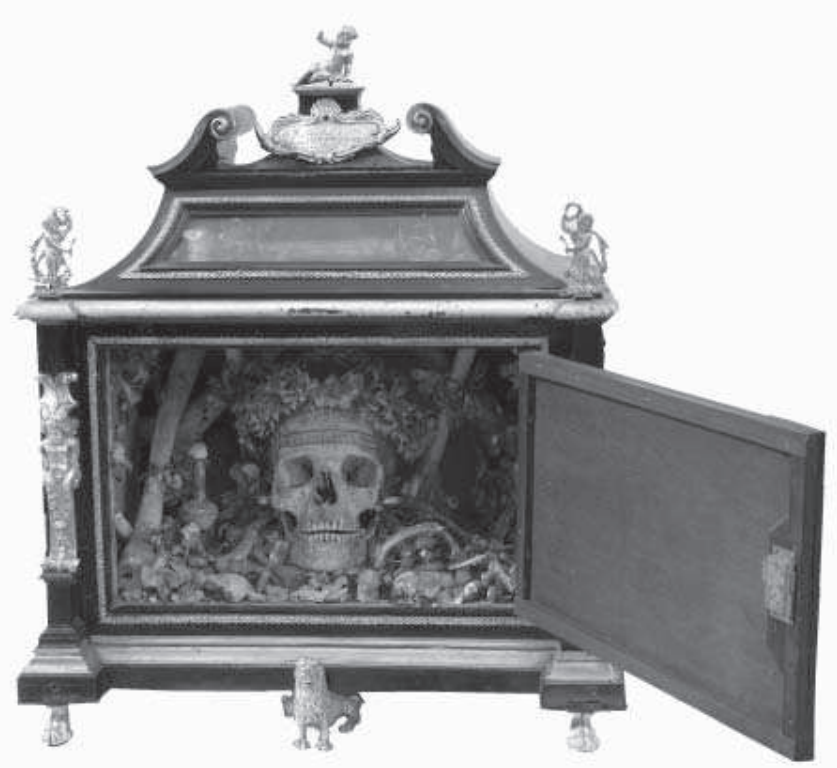

4. Urna completa.

Mucho más cercano en el tiempo, con ocasión de disponer el beato Manuel González García, obispo de Málaga, la ceremonia de consagración de la catedral para el 12 de abril de 1921, se emplearon fragmentos y lascas provenientes de las reliquias de San Mauricio, San Flaviano y Santa Dianesa, que fueron trasladadas procesionalmente al efecto en el templete eucarístico que servía para el monumento de Jueves Santo ${ }^{26}$.

Por último el 25 de mayo de 2009, con ocasión de la consagración de la remozada parroquia de Olías, se depositó bajo el altar y dentro de una pequeña teca una reliquia del santo en cuestión, junto a otra del beato Juan Duarte, en un curioso paralelismo que asocia simbolicamente a dos mártires de épocas muy distantes. Con ello se ha seguido las directrices recogidas en el Misal Romano, renovado, que confirma la validez del "....) uso de colocar bajo los altares que se van a dedicar, las reliquias de los santos ${ }^{27}$. Colocados en ese lugar, los restos sacros vienen a significar como el martirio de los miembros de la Iglesia tienen su sentido pleno en conjunción con el sacrificio de su cabeza, constituida por Cristo: siendo además una expresión simbólica de comunión y fidelidad a la fe llevadas hasta el extremo.

26 A.C.M. AA.CC. 12 de abril de 1921, fol. 187

27 Vide: Directorio sobre la piedad popular y la liturgia, principios y orientaciones. Congregación para el Culto Divino y la Disciplina de los Sacramentos. Ciudad del Vaticano, 2002, capítulo VI, págs. 236- 237. 
En cuanto al resto de las reliquias de otros santos que atesora la urna de San Flaviano, ya hemos comprobado como le siguen en importancia las de Santa Justina, constituida por la canilla de la que ya hemos hecho mención al describir el ático del relicario y de la redomita de vidrio azulado que se encuentra fijada a la izquierda del cráneo del mártir, con toda la apariencia de ser un objeto auténtico de época romana. También en las antedichas vitrinas exteriores del conjunto, se pueden contemplar, convenientemente adornadas con lazadas y quincallas conformando una hojarasca de volutas barrocas, una serie de reliquias menores distribuidas de la siguiente forma. En la de lado derecho un octágono superior presenta un busto perdido realizado, según se lee en una fajita de papel escrita en italiano, con pasta de reliquias, o sea el polvo y los pequeños fragmentos de ellas desprendidos, amasados con alguna engrudo calcáreo y posteriormente modelado. Bajo éste se encuentra otro, de líneas más disformes, confeccionado del mismo material según vuelve a rezar la consabida leyenda: pasta di reliq. di piú ss. mart., en medio del cual existe un relieve circular con la Virgen y el Niño, rodeado de pétalos y flores pintadas. Otros cuatro, más pequeños e igualmente redondeados aparecen delimitando los ángulos del dicho expositor. EI colocado en la esquina superior izquierda parece representar a una santa arrodillada con un angelito y una inscripción borrosa en la que sólo se advierte: C...RVND. En el de la derecha aparecen dos figuras. En el inferior izquierdo una imagen, un tanto hierática, que cabe identificar con la Virgen y el Niño y la inscripción: ROM. Por su parte, el enfrentado a éste contiene una figura frontal, de cuerpo entero, sosteniendo un báculo en su mano diestra y las letras: IVSM...S...C. A lado y lado de la vitrina se encuentran fijados dos huesos con sus respectivas bandas identificativas. El de la izquierda contiene el nombre de ISIDORI $M$ y el otro el de S. SERVAND (...).

En cuanto a la vitrina izquierda, en su centro superior campea un busto de la Virgen con las manos entrecruzadas y los ojos y la boca coloreados. Como el del otro lateral también posee flores pintadas alrededor y dentro del octógono que ocupa, perfilado con líneas blancas y rojas. Bajo ella el relieve contenido en el receptáculo inferior parece mostrar a tres figuras conformando alguna escena. Todos ellos vuelven a tener una banda de papel donde se recuerda de qué elemento están confeccionados: pasta di reliq di piú ss. $M$. En el ángulo superior izquierdo de esta vitrina existe otro relieve de la dicha materia con una mujer doliente ${ }^{28}$. En el derecho el busto de un personaje acompañado del Espíritu Santo y rodeado de dos plantas. En el situado en el ángulo inferior izquierdo la Virgen con el Niño sedente y en el contrario a éste, un busto de un santo barbado con un atributo y una inscripción ilegibles. En esta ocasión los huesos fijados a los lados de la composición parecen pertenecer, el de la derecha a (...) phemia v. y el frontero a Benedicta.

Ninguno de estos relieves y reliquias son mencionados, como hemos podido comprobar, en la documentación que avaló su entrega al cabildo malagueño a fines

28 ¿La Dolorosa? 
del siglo XVII, donde tan sólo primaron la consideración de las insignes que recibieron los restos de San Flaviano y, en menor medida, los de Santa Justina ${ }^{29}$. Ambos, después de casi tres siglos justos de permanencia en la catedral de Málaga, bien podría decirse que han ganado carta de ciudadanía malagueña aún cuando, y nunca mejor dicho, duermen el sueño de los justos olvidados del pueblo y del clero a quienes se encomendó guardar su memoria y su culto.

29 Referencia de estos cultos se hace en SÁNCHEZ LÓPEZ, J.A.: "Juventud invicta, infancia triunfante. Hagiografía, mito, presencia y culto en las catedrales españolas del Barroco”, en RAMALLO ASENSIO, G. (coord.): La catedral guía mental y espiritual de la Europa Barroca Católica, Murcia 2010, págs. 102-208. 